\title{
Description of Nearly Completed Mitochondrial Genome Sequences of the Garden Chafer Polyphylla laticollis manchurica, Endangered in Korea (Insecta: Coleoptera)
}

\author{
Min Jee Kim ${ }^{1}$, Ki-Gyoung $\mathrm{Kim}^{2}$, and $\mathrm{Iksoo} \mathrm{Kim}^{1 *}$ \\ ${ }^{1}$ College of Agriculture \& Life Sciences, Chonnam National University, Gwangju 500-757, Korea \\ ${ }^{2}$ Biological Resources Research Department, National Institute of Biological Resources, Incheon, 404-708, Korea
}

\section{Abstract}

In this study, we present the nearly complete mitogenome sequences of the garden chafer, Polyphylla laticollis manchurica, which is listed as an endangered species in Korea. The $P$. I. manchurica mitogenome, which includes unfinished whole A+T-rich region and a partial srRNA was 14,473-bp long, possessing typical sets of genes (13 PCGs, 22 tRNA genes, and 2 rRNA genes). Gene arrangement of the $P$. I. manchurica mitogenome was identical to the common one found in the majority of insects. The 5 bp-long motif sequence (TAGTA) that has been suggested to be the possible binding site for the transcription termination peptide for the major-strand was also found in the $P$. I. manchurica mitogenome between tRNA ${ }^{\text {Ser }}(\mathrm{UCN})$ and ND1. The start codon for COI gene and ATPase8 was designated as a typical TTG. All tRNAs of the P. I. manchurica showed a stable canonical clover-leaf structure of other mt tRNAs, except for tRNA ${ }^{\text {Ser }}(A G N)$, DHU arm of which could not form stable stemloop structure. As has been previously determined, the high $A / T$ content was unanimously observed in $P$. I. manchurica in terms of $A / T$ bias in the third codon position $(73.5 \%)$ compared with the first (66.4\%) and second codon position (66.2\%). The PCGs encoded in major-strands are slightly T-skewed, whereas those of the minor-strand are A-skewed, indicating strand asymmetry in nucleotide composition in the Coleoptera including $P$. I. manchurica.

Received : 00 A 2013

Accepted : 00 A 2013

\section{Keywords:}

Mitochondrial genome, Polyphylla laticollis manchurica, Garden chafer, A/T bias

\section{Introduction}

Animal mitochondrial genomes (mitogenomes) are approximately 16 20 kbp, and are encoded with a remarkably conserved set of 37 genes: 13 protein-coding genes (PCGs), two ribosomal RNA (rRNA) genes, and 22 transfer RNA (tRNA) genes, and one major non-coding sequence, which is termed the control region (Boore, 1999). This control region in insect instead is called

\section{${ }^{*}$ Corresponding author.}

Iksoo Kim

College of Agriculture and Life Sciences, Chonnam National University, Gwangju 500-757, Republic of Korea.

Tel: +82-62-530-2073 / FAX: +82-62-530-2079

E-mail: ikkim81@chonnam.ac.kr 
as the $\mathrm{A}+\mathrm{T}$-rich region due to the high adenine and thymine $(\mathrm{A} / \mathrm{T})$ content, and in fact, this region contains the highest $\mathrm{A} / \mathrm{T}$ content of any region of the mitogenomes in insects (Kim et al., 2010).

The mitogenome information has greatly been devoted to our understanding of several fields of biology (i.e., comparative and evolutionary genomics, molecular evolution, and phylogenetics). However, still newly sequenced insect mitogenome information provides us with new insights into genomic structures (Wan et al., 2012) and the evolutionary relationships of several levels of taxonomic groups (Kim et al., 2011; Cameron et al., 2009), and gene arrangement (Wang et al., 2013).

Up to now, more than 250 mitogenome sequences have been determined from a variety of insects, but this list includes only $\sim 34$ coleopteran species (http://www.ncbi.nlm.nih.gov/ genomes/ORGANELLES). Considering that the suborder Polyphaga contains the vast majority of beetle diversity, with at least 300,000 described species ( $90 \%$ of the beetles) belonging to more than 100 families in four infraorders (Hammond, 1992), genomic information is extremely limited. In particular, the complete mitogenome sequence of the infraorder Scarabaeiformia in Polyphaga is available only for two species (Cameron et al., 2009; Sheffield et al., 2009). Recently, Kim et al. (2013a, 2013b) additionally reported two complete mitogenome sequences of Scarabaeiformia, the whiter-spotted flower chafer, Protaetia brevitarsis (Scarabaeidae) and the two-spotted stag beetle, M. blanchardi (Lucanidae).

In this paper, we report the mitogenome sequence of Polyphylla laticollis manchurica to describe the genome via comparison to those of pre-existing coleopteran insects in terms of whole genome organization, arrangement, and the major characteristics of individual genes. $P$. 1. manchurica is distributed throughout Korea, including Jeju Island, and also in Mongolia and japan, as well as Eastern China (Won et al., 1998). Due to the rarity the species is listed as an endangered species in Korea (Won et al., 1998).

\section{Materials and Methods}

\section{Specimen collection and genomic DNA extraction}

The garden chafer, Polyphylla laticollis manchurica (Scarabaeiformia: Scarabaeidae), was collected in Yeongwol,
Gwangwondo-Province in Korea. P. 1. manchurica is listed as a first degree endangered species in Korea, and thus, proper permission was obtained from relevant supervisory office before collection. Total genomic DNA was extracted using the Wizard $^{\mathrm{TM}}$ Genomic DNA Purification kit (Promega, USA) following the manufacturer's instruction.

\section{PCR amplification, cloning, and sequencing}

Three short fragments, corresponding each about 500 700 bp were amplified from three genes, such as COI (SF1), CytB (SF2), and srRNA (SF3) (Fig. 1). Primers for these

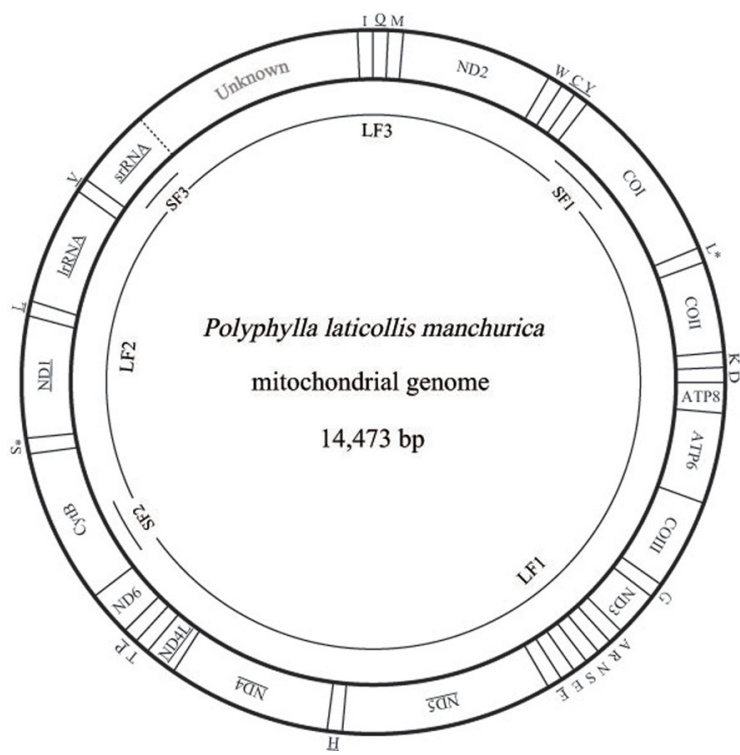

Fig. 1. Circular map of the mitochondrial genomes of Polyphylla laticollis manchurica. The abbreviations for the genes are as follows: COI, COII, and COIII refer to the cytochrome oxidase subunits, CytB refers to cytochrome B, ATP6 and ATP8 refer to subunits 6 and 8 of $\mathrm{F}_{0}$ ATPase, and ND1 $\sim 6$ refer to components of NADH dehydrogenase. tRNAs are denoted as one-letter symbols consistent with the IUPACIUB single letter amino acid codes. The one-letter symbols L, $\mathrm{L}^{*}, \mathrm{~S}$ and $\mathrm{S}^{*}$ denote tRNA ${ }^{\mathrm{Leu}}(\mathrm{CUN}), \mathrm{tRNA}^{\mathrm{Leu}}(\mathrm{UUR}), \mathrm{tRNA}^{\mathrm{Ser}}(\mathrm{AGN})$, and $\mathrm{tRNA}^{\mathrm{Ser}}(\mathrm{UCN})$, respectively. Gene names that are not underlined indicate a clockwise transcriptional direction, whereas underlined genes indicate a counter-clockwise transcriptional direction. The $P$. 1 . manchurica mitogenome was amplified each from three short (SF1, SF2, and SF3) and three long (LF1, LF2, and LF3) overlapping fragments, shown as single lines within a circle. The unknown region that possibly contains partial srRNA and the $\mathrm{A}+\mathrm{T}$-rich region is shaded. 
Table 1. List of primers used to amplify and sequence the mitochondrial genomes of Polyphylla laticollis manchurica

\begin{tabular}{|c|c|c|c|c|}
\hline Fragment name & Primer name & Direction & Position & Sequence $\left(5^{\prime}-3^{\prime}\right)$ \\
\hline \multicolumn{5}{|l|}{ Short fragments } \\
\hline \multirow[t]{2}{*}{ SF1 } & LCO 1490 & $\mathrm{~F}$ & $1423-1447$ & GGTCAACAAATCATAAAGATATTGG \\
\hline & $\mathrm{HCO} 2198$ & $\mathrm{R}$ & $2375-2401$ & TAAACTTCAGGGTGACCAAAAAATCA \\
\hline \multirow[t]{2}{*}{$\mathrm{SF} 2$} & PBSF3F0720 & $\mathrm{F}$ & $6980-6999$ & CCTATATAACGAATATCTTG \\
\hline & PBSF3R0720 & $\mathrm{R}$ & $7409-7428$ & AATGCAGGAATATTAACTGC \\
\hline \multirow[t]{2}{*}{ SF3 } & PBSF5F & $\mathrm{F}$ & $13946-13968$ & GACGGGCAATATGTGCATATTTT \\
\hline & PBSF5R & $\mathrm{R}$ & $14476-14497$ & TGCCAGCAATTGCGGTTATACA \\
\hline \multicolumn{5}{|l|}{ Long fragments } \\
\hline \multirow[t]{2}{*}{ LF1* } & PLCOIF3 & $\mathrm{F}$ & $1836-1861$ & TATTTTTAGCCTCCATCTTGCAGGAA \\
\hline & PL8KbR1 & $\mathrm{R}$ & $10503-10526$ & AGCAATCAGCCATAGTTTACATCA \\
\hline \multirow[t]{2}{*}{ LF2* } & PL8KbF3 & $\mathrm{F}$ & $10779-10801$ & ATTATGGGGCGGATTCGCAGTTG \\
\hline & SF5R & $\mathrm{R}$ & $14474-14495$ & TGCCAGCAATTGCGGTTATACA \\
\hline \multirow[t]{2}{*}{ LF3 } & SF5F3 & $\mathrm{F}$ & $14309-14330$ & ACATTTCCAATAATAGGGTATC \\
\hline & PLCOIR4 & $\mathrm{R}$ & $1615-1634$ & CCGAATCCCCCGATTATAAT \\
\hline \multicolumn{5}{|l|}{ Internal primers } \\
\hline \multirow[t]{7}{*}{ LF3 } & PLSF1F & $\mathrm{F}$ & $8-25$ & TGTCTGAAAAAGAGTCAC \\
\hline & PLSF1R & $\mathrm{R}$ & $714-736$ & ATATGATTAATTGAGGAGTAAGC \\
\hline & PLSF2F & $\mathrm{F}$ & $561-582$ & TCCTTAATTATACTGACCTGGC \\
\hline & PLSF2R & $\mathrm{R}$ & $1109-1128$ & ATTTTAAAGGTGGTCTTGAG \\
\hline & PLSF3F & $\mathrm{F}$ & 995-1012 & CAAAATATTCACCATAGC \\
\hline & PLSF4R & $\mathrm{R}$ & $1640-1660$ & CTAGTATTAGGGGTACTAGTC \\
\hline & PLSRRNAF & $\mathrm{F}$ & $14085-14108$ & ATCTATGCGCTGTACCTTGATCTG \\
\hline
\end{tabular}

*Sequencing was completed by shotgun method.

short fragments were designed via the alignment of several coleopteran mitogenomes sequenced in their entirety. These short fragments were amplified with AccuPower® PCR PreMix (Bioneer, Korea) using an initial denaturation at $94^{\circ} \mathrm{C}$ for 4 min, followed by 35 cycles of $30 \mathrm{~s}$ denaturation at $94^{\circ} \mathrm{C}, 40 \mathrm{sec}$ annealing at $50-55^{\circ} \mathrm{C}$, and a $60 \mathrm{sec}$ extension at $72^{\circ} \mathrm{C}$. The final extension step was continued for $8 \mathrm{~min}$.

Using the sequence information obtained from the short fragments, three primer sets specific to each species were designed to amplify three long fragments (LF1 LF3) which overlapped with the short fragments (SF1 SF3). PCR cycles were as follows: denaturation for $2 \mathrm{~min}$ at $96^{\circ} \mathrm{C}$, followed by 30 cycles of $10 \mathrm{sec}$ at $98^{\circ} \mathrm{C}$ and $15 \mathrm{~min}$ at $58-65^{\circ} \mathrm{C}$, and a final 10 min extension at $72^{\circ} \mathrm{C}$. In order to sequence the long fragments, both primer walking and shotgun approaches were used, because the success of sequencing varied depending on fragments. Nevertheless, both approaches were unsuccessful for LF3, and, thus, the partial LF3 that encompasses the 5'-end of the srRNA and the whole A+T-rich region was unfinished. We believe this may have happened because this region is exceptionally long, containing unexpectedly long repeat regions and a high $\mathrm{A} / \mathrm{T}$ content, considering previous sequence results of other coleopteran species, such as $P$. brevitarsis and M. blanchardi (Kim et al., 2013a, 2013b). Primer information for each short fragment, long fragment, and internal primers for primer walking are provided (Table 1). 
For the primer walking method, internal primers were directly used to complete the sequences of the long fragment subsequent to purification with OIAquick PCR Purification Kit (Qiagen, USA). For the shotgun approach the long PCR fragments were subjected to shearing into $1 \sim 5 \mathrm{~kb}$ fragments (Gene Machine, USA) and were cloned into the pUC118 vector (Takara Biomedical, Japan). Each resultant plasmid DNA was isolated using a Wizard Plus SV Minipreps DNA Purification System (Promega, USA). DNA sequencing was conducted using the ABI PRISM $^{\circledR}$ BigDye $^{\circledR}$ Terminator v3.1 Cycle Sequencing Kit and the ABI PRISM $^{\circledR} 3100$ Genetic Analyzer (PE Applied Biosystems, USA).

\section{Gene identification and structure}

The boundary of individual thirteen mitochondrial protein-coding genes (PCGs) and individual two rRNAs were determined through the alignment of the homologous sequences of known full-length coleopteran mitochondrial genome sequences using the CLUSTAL X program (Thompson et al., 1997). The nucleotide sequences of the PCGs were translated on the basis of the invertebrate mtDNA genetic code (http://www.ncbi.nlm.nih.gov/Taxonomy/ taxonomyhome.html/index.cgi?chapter=cgencodes). The translated amino acid sequence was further utilized to identify and delimitate the 13 PCGs. The tRNA genes were identified by their predicted cloverleaf secondary structure and anticodon sequences using the tRNAscan-SE version 1.1 with the option of invertebrate codon predictors and a cove score cut off of 1 (Lowe and Eddy 1997). The tRNA $^{\text {Ser }}(\mathrm{AGN})$ and tRNA ${ }^{\text {Asn }}$ were initially identified through alignment of the nucleotide sequences of the tRNA genes of known full-length coleopteran mtDNA sequences, and were further confirmed by hand-drawing their secondary cloverleaf structure by inspection of respective anticodon sequences. The sequence data determined in this study have been deposited to GenBank under the accession number KF544959.

\section{Comparative mitochondrial gene analyses}

We compared 35 species of coleopteran insects including the currently sequenced $P$. 1 . manchurica. Nucleotide composition of each gene, whole genome, and each codon position of PCGs were calculated using DNASTAR (Burland, 2000). Frequencies of both codon and amino acid were calculated using SWAAP ver. 1.0.3 (http://www.bacteriamuseum.org/SWAAP/SwaapPage. $\mathrm{htm})$. Gene overlap and intergenic-space sequences were handcounted. Nucleotide composition, termed "compositional skew" was calculated for the PCGs between two strands, and the whole genome with the EditSeq program included in the Lasergene software package (www.dnastar.com) using the following formula proposed by Perna and Kocher (1995): GC-skew $=(\mathrm{G}-$ $\mathrm{C}) /(\mathrm{G}+\mathrm{C})$ and AT-skew $=(\mathrm{A}-\mathrm{T}) /(\mathrm{A}+\mathrm{T})$, where $\mathrm{C}, \mathrm{G}, \mathrm{A}$, and $\mathrm{T}$ are the frequencies of the four bases.

\section{Results and discussion}

\section{General features}

The Polyphylla laticollis manchurica mitogenome contains typical sets of genes, such as 13 PCGs, 22 tRNA genes, and 2 rRNA genes (Table 2). Typically, coleopteran insects contain one large non-coding region, named the A+T-rich region in insects, but we were unsuccessful in sequencing this region and the neighboring partial 5'-region of srRNA. In GenBank, a substantial number of incomplete mitogenome sequences lacking the $\mathrm{A}+\mathrm{T}$-rich region and neighboring sequences are registered and published as incomplete mitogenomes (Sheffield et al., 2008). Possible reasons for such failure may be the presence of secondary structural motifs and the excessive length of the $\mathrm{A}+\mathrm{T}$ region. Several coleopteran species have been reported to have an extraordinary long $\mathrm{A}+\mathrm{T}-$ rich region and an extra non-coding sequences neighboring to the region. For example, the seven-spotted lady beetle has been reported to have a 4,469 bp-long A+T-rich region which is composed of a 2,214 bp of non-repeat region and a 2,255 bp repeat region (Kim et al., 2012). Furthermore, the whiter-spotted flower chafer, $P$. brevitarsis, has a 5,646-bp long A+T-rich region which is composed of a 1,804 bp non-repeat region and a 3,841 bp repeat region (Kim et al., 2013a). In addition, insect mitogenomes infrequently contain substantially longer intergenic spacer sequences which are composed of tandem repeat unit located neighboring to the A+T-rich region. For example, the Korean firefly, Pyrocoelia rufa, has a 1724-bp long intergenic spacer (Bae et al., 2004). More extreme case is the two-spotted stag beetle, 
Table 2. Summary of the mitochondrial genome of Polyphylla laticollis manchurica

\begin{tabular}{|c|c|c|c|c|c|c|c|}
\hline \multirow{2}{*}{ Gene } & \multirow{2}{*}{ D } & \multirow{2}{*}{$\begin{array}{c}\text { Nucleotide } \\
\text { number }\end{array}$} & \multirow{2}{*}{ Size (bp) } & \multirow{2}{*}{ Anticodon } & \multicolumn{2}{|c|}{ Codon } & \multirow{2}{*}{ O/s } \\
\hline & & & & & Start & Stop & \\
\hline tRNAlle & $\mathrm{F}$ & $1-63$ & 63 & GAT (29-31) & & & \\
\hline tRNAGIn & $\mathrm{R}$ & $61-129$ & 69 & TTG (97-99) & & & +3 \\
\hline tRNAMet & $\mathrm{F}$ & $129-197$ & 69 & CAT (159-161) & & & +1 \\
\hline ND2 & $\mathrm{F}$ & $198-1205$ & 1008 & & ATA & TAA & \\
\hline tRNATrp & $\mathrm{F}$ & $1220-1286$ & 67 & TCA (1251-1253) & & & -15 \\
\hline tRNACys & $\mathrm{R}$ & $1279-1339$ & 61 & GCA (1307-1309) & & & +8 \\
\hline tRNATyr & $\mathrm{R}$ & $1341-1405$ & 65 & GTA (1372-1374) & & & -1 \\
\hline $\mathrm{COI}$ & $\mathrm{F}$ & $1405-2943$ & 1539 & & TTG & TAA & \\
\hline tRNALeu(UUR) & $\mathrm{F}$ & $2939-3003$ & 65 & TAA (2968-2970) & & & +5 \\
\hline COII & $\mathrm{F}$ & $3004-3688$ & 685 & & ATA & T-tRNA & \\
\hline tRNALys & $\mathrm{F}$ & $3689-3759$ & 71 & CTT (3719-3721) & & & \\
\hline tRNAAsp & $\mathrm{F}$ & $3768-3834$ & 67 & GTC (3800-3802) & & & -0 \\
\hline ATPase8 & $\mathrm{F}$ & $3835-3990$ & 156 & & TTG & TAG & \\
\hline ATPase6 & $\mathrm{F}$ & $3987-4658$ & 672 & & ATA & TAA & +4 \\
\hline COIII & $\mathrm{F}$ & $4658-5445$ & 788 & & ATG & TA-tRNA & +1 \\
\hline tRNAGly & $\mathrm{F}$ & $5445-5507$ & 63 & TCC (5475-5477) & & & \\
\hline ND3 & $\mathrm{F}$ & $5508-5861$ & 354 & & ATA & TAG & \\
\hline tRNAAla & $\mathrm{F}$ & $5860-5923$ & 64 & TGC (5889-5891) & & & +2 \\
\hline tRNAArg & $\mathrm{F}$ & $5924-5989$ & 66 & TCG (5953-5955) & & & \\
\hline tRNAAsn & $\mathrm{F}$ & $5987-6051$ & 65 & GTT (6018-6020) & & & +3 \\
\hline tRNASer(AGN) & $\mathrm{F}$ & $6052-6118$ & 67 & TCT (6088-6090) & & & \\
\hline tRNAGlu & $\mathrm{F}$ & $6119-6181$ & 63 & TTC (6149-6151) & & & \\
\hline tRNAPhe & $\mathrm{R}$ & $6180-6245$ & 66 & GAA (6211-6213) & & & +2 \\
\hline ND5 & $\mathrm{R}$ & $6246-7964$ & 1719 & & ATT & TAA & \\
\hline tRNAHis & $\mathrm{R}$ & $7965-8028$ & 64 & GTG (7996-7998) & & & \\
\hline ND4 & $\mathrm{R}$ & $8028-9362$ & 1335 & & ATG & TAA & +1 \\
\hline ND4L & $\mathrm{R}$ & $9356-9646$ & 291 & & ATG & TAA & +7 \\
\hline tRNAThr & $\mathrm{F}$ & $9655-9718$ & 64 & TGT (9686-9688) & & & \\
\hline tRNAPro & $\mathrm{R}$ & $9719-9783$ & 65 & TGG (9750-9752) & & & \\
\hline ND6 & $\mathrm{F}$ & $9785-10288$ & 504 & & ATC & TAA & -1 \\
\hline CytB & $\mathrm{F}$ & $10288-11430$ & 1143 & & ATG & TAG & +1 \\
\hline tRNASer(UCN) & $\mathrm{F}$ & $11429-11493$ & 65 & TGA (11458-11460) & & & +2 \\
\hline ND1 & $\mathrm{R}$ & $11514-12467$ & 954 & & ATA & TAA & \\
\hline tRNALeu(CUN) & $\mathrm{R}$ & $12528-12465$ & 64 & TAG (12499-12497) & & & \\
\hline IrRNA & $\mathrm{R}$ & $12466-13814$ & 1286 & & & & \\
\hline tRNAVal & $\mathrm{R}$ & $13815-13884$ & 70 & TAC (13851-13853) & & & \\
\hline srRNA (incomplete) & $R$ & $13885-14473$ & 589 & & & & \\
\hline$A+T$-rich region & & unfinished & & & & & \\
\hline
\end{tabular}

Direction (D) of gene is presented as $\mathrm{F}$ for forward and $\mathrm{R}$ for reverse direction.

tRNA abbreviations follow the IUPAC-IUB three-letter code.

$\mathrm{O} / \mathrm{S}$, number of overlapping(+)/intergenic space sequence(-). 


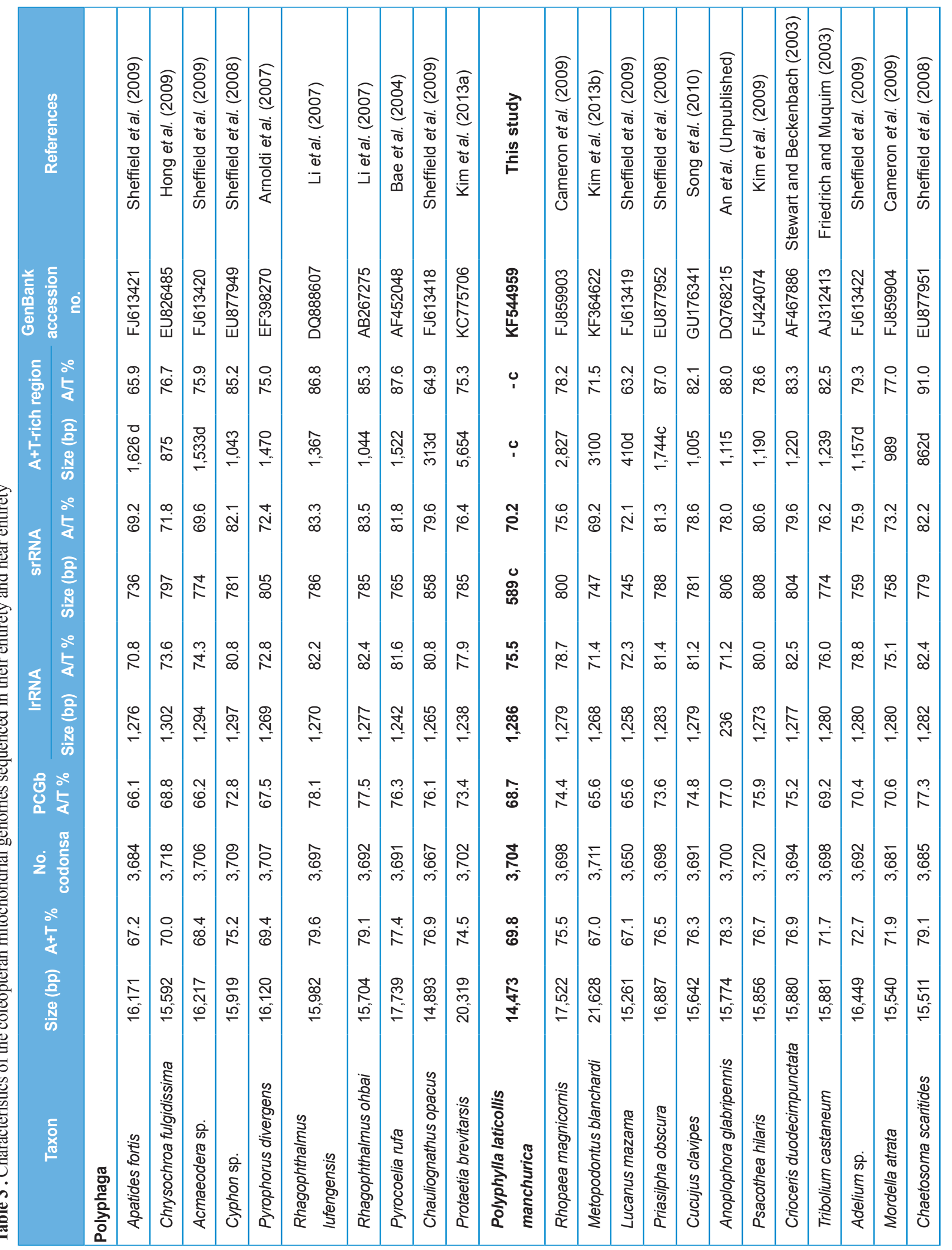




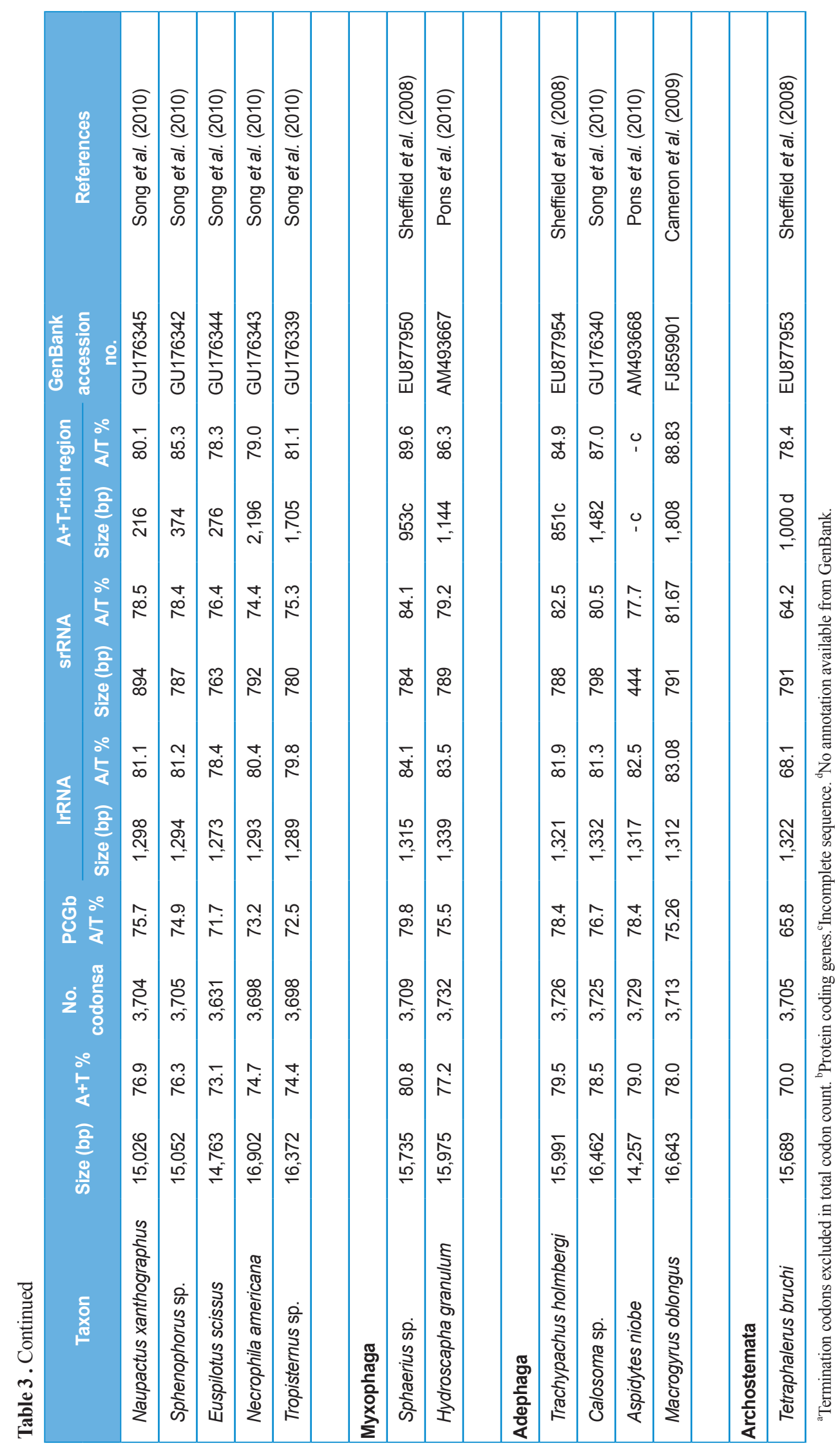




\section{Polyphaga \\ Apatides fortis \\ Chrysochroa fulgidissima \\ Acmaeodera sp. \\ Cyphon sp. \\ Pyrophorus divergens \\ Rhagophthalmus lufengensis \\ Rhagophthalmus ohbai \\ Pyrocoelia rufa \\ Chauliognathus opacus \\ Protaetia brevitarsiss}

Polyphylla laticollis manchurica

Rhopaea magnicornis

Metopodontus blanchardi

Lucanus mazama

Priasilpha obscura

Cucujus clavipes

Anoplophora glabripennis

Psacothea hilaris

Crioceris duodecimpunctata

Tribolium castaneum

Adelium sp.

Mordella atrata

Chaetosoma scaritides

Naupactus xanthographus

Sphenophorus sp.

Euspilotus scissus

Necrophila americana

Tropisternus sp.

\section{Myxophaga}

Sphaerius sp.

Hydroscapha granulum

\section{Adephaga \\ Trachypachus holmbergi \\ Calosoma sp. \\ Aspidytes niobe \\ Macrogyrus oblongus \\ Archostemata}

Tetraphalerus bruchi

$$
\mathrm{ND} 1 \rightarrow \quad \text { tRNA }^{\mathrm{Ser}}(\mathrm{UCN}) \rightarrow
$$

CTTATTTAGTTAACAAATTTTAGTATTAEAT TTGTGTTAGGCAATAAAATTTAGTATAAGT I TACAGTTAACTAACAAAATTTAGTACTTA_A ATTATTTAGTTGATTAAATTTAGTAATAAGT TTTGTTTAGTTAATTAATTTTAGTATAAGIT ATTATTTAGTTAATAAAATTTAGTATAAAAS ATTATTTAGTTAATAAAATTTAGTATTAEGT ATAATTTAGTTAATTAATTTAGTAAAGTTE TTAATTTAGTCAATAAATTTTAGTAAAGTTE TTTATTTAATGGATTAAATTTAGTATATTTA TTGATTTAATGCATGAATTTTAGTAGTCTAA ATAATATAATGTATAAAATTTAGTAAAAAAE. CTAATTTAGTGAATAAAATTTAGTAGTAAGC TCTATTTAGTGAATAAAAAATAGTAAACAGG TTTATTTAGTCAATAAAATTTAGTACAAGTT ATGGTTTAGTTAATTAATTTTAGTATAAGTC TTACTTTAGTTAATAAAATTTAGTATEAGTT. TTGCTTTAGTTAATAAAATTTAGTATA_AGT TTTATTTAGTTAATAAAATTTAGTACAAETT TTAATTTAGTTAATAAAATTTAGTATAAACT TTATTGTAGTTAATAAAAATTAGTATAAACT TTATTTTAGTTAAGTTTTTTAGTAAAAACT TTAAATTAGTTAATAAAATTTAGTATA_A-GC AATATTTAGTTAATTATTTTTAGTACGTTTA ATTTTATACTTAATTATTTTTAGTACTAA_A TTGGCTTAGTTAATAAAATTTAGTATA_AGTT TTGATTTAGTTAATAAAATTTAGTAGTAEGT ATTATTTAGTTAATAAAATTTAGTATAEGTT.

\section{ATTATATAATGAAATATTTTTAGTAATAAAT} TTAATTTAGTGAATTATTTTTAGTAATTAEA

\section{TTAATTTAGTGAATTTTTTTAGTAAAA_AGI TTAATTTAGTGAATTATTTTTAGTAAAGTIA TTAATTTAGTCAATTTTTTTTAGTAAAAATT TTGATTTAGTGAATTTTTTTAGTAAAGTTA.}

\section{CGCTTTAAGTTAATTATCTATAGTATAGGTT.}

Fig. 2. Alignment of the internal spacer region located between ND1 and $\mathrm{tRNA}^{\mathrm{Ser}}(\mathrm{UCN})$ from coleopteran species, including Polyphylla laticollis manchurica. The boxed nucleotides indicate the conserved pentanucleotide region (TAGTA) detected in coleopteran insects. Underlined and dotted nucleotides, respectively, indicate the adjacent partial sequences of the ND1 gene and tRNA ${ }^{\text {Ser }}(\mathrm{UCN})$ gene. The arrows indicate the transcriptional direction. 
which contains a 4,051-bp long, large non-coding sequence located between tRNA ${ }^{\text {Ile }}$ and tRNA ${ }^{\text {Gln }}$, along with a 3,100-bp long $\mathrm{A}+\mathrm{T}$-rich region, resulting in a genome size of 21,628 bp, which is at least $5 \mathrm{~kb}$ larger than typical animal mitogenomes (Kim et al., 2013b). Considering these, it would be a reasonable speculation that the unfinished region is unusually large. The secondary structural motifs in the $P$. 1. manchurica mitogenome might be another source that prevented the polymerases correctly passing across this region, resulting in casual amplification and making subsequent sequencing impossible (Carapelli et al., 2006). Several coleopteran mitogenomes which have extraordinary long A+T-rich region also have several long repeat sequences (Kim et al., 2012; 2013a, 2013b). These repeat sequences can easily form stem-andloop structures (Zhang and Hewitt, 1997; Kim et al., 2007), and thus, the unfinished $\mathrm{A}+\mathrm{T}$-rich region, along with the neighboring region of the $P$. 1. manchurica mitogenome is highly likely to have such motifs. Nevertheless, this failure was not fully understood, considering our previous success in sequencing this region from several coleopteran insects (Kim et al., 2012, 2013a, 2013b).

The P. 1. manchurica mitogenome has an identical gene order that has been found in the majority of insect species (Boore, 1998). Among 35 complete or nearly complete coleopteran mitogenomes (Table 3), only Tribolium castaneum differs from the most common type, by the movement of the tRNA ${ }^{\text {Glu }}$ to a position 3'-downstream of tRNA ${ }^{\text {Phe }}$, thus resulting in an order of tRNA $^{\text {Phe }}$ and tRNA ${ }^{\text {Glu }}$, rather than the order tRNA ${ }^{\text {Glu }}$ and $\mathrm{tRNA}^{\text {Phe }}$ (Friedrich and Muquim 2003).

\section{Overlapping and intergenic spacer sequences}

The P. 1. manchurica mitochondrial genes harbor a total of 47 bp of intergenic spacer sequences, which are spread over six regions, ranging in size from 1 to $20 \mathrm{bp}$, with the longest being located between tRNA ${ }^{\text {Ser }}(\mathrm{UCN})$ and ND1 (Table 2). Similar sized intergenic spacer sequences are found in the majority of sequenced coleopteran insects (16 $22 \mathrm{bp})$, except for those of Rhagophthalmus lufengensis and $R$. ohbai, which are only 5-bp long (Li et al., 2007). Previously, it has been shown that the region contains a 5 bp-long motif sequence (TAGTA) in the coleopteran insects (Sheffield et al., 2008). Our additional analysis, including all available coleopteran species and P. 1. manchurica, consistently revealed a motif sequence in the region (Fig. 2). This 5-bp consensus sequence was suggested to be the possible binding site for mtTERM, the transcription termination peptide, with the consideration that the intergenic spacer sequence is detected at the end site of the major-strand coding region in the circular mtDNA (Taanman, 1999).

Next longer intergenic spacer sequence is located between ND2 and tRNA ${ }^{\text {Trp }}$ as 14 bp (Table 2). A search on this region from other coleopteran insects has shown fluctuating length: only a few spacer sequences in most species (e.g., 4 bp in Pyrophorus divergens; Arnoldi et al., 2007), abuttal between the two genes (e.g., Psacothea hilaris; Kim et al., 2009), and overlapping between the two genes ( $2 \mathrm{bp}$ in Tribolium castaneum; Friedrich and Muqim, 2003). An exceptional case is that of $P$. rufa, which has a 1,724-bp long tandem repeat unit between the two genes (Bae et al., 2004). The P. 1. manchurica mitochondrial genes overlap in a total of $33 \mathrm{bp}$ at 12 locations, with the longest overlap measuring $8 \mathrm{bp}$, and located between $\mathrm{tRNA}^{\mathrm{Trp}}$ and $\mathrm{tRNA}^{\mathrm{Cys}}$. Similarly-sized overlapping sequences are also detected in several coleopteran insects (e.g., P. brevitarsis; Kim et al., 2013a; Metopodontus blanchardi; Kim et al., 2013b), but abuttal (P. rufa; Bae et al., 2004) and overlapping regions (8 bp in Pyrophorus divergens; Arnoldi et al., 2007) are also found between the two tRNAs.

\section{Start and stop codon}

The P. 1. manchurica mitogenomes harbors 3,704 codons, excluding termination codons, and this number is identical to those of Naupactus xanthographus (Song et al., 2010) and most similar to those of Sphenophorus sp. (3,705 codons; Song et al., 2010) and Tetraphalerus bruch (3705 codons; Sheffield et al., 2008).

All PCGs, with the exception of COI and ATPase8 of the P. 1 . manchurica mitogenomes have the typical ATN codon (Table 2). The initiation site for the COI gene and the precedent tRNA $^{\text {Tyr }}$ does not harbor the typical start codon, except for the infrequent, but typical invertebrate start codon TTG that is located at the beginning region of the COI, overlapping one nucleotide with the 5'-end of the tRNA ${ }^{\text {Tyr }}$ (Fig. 3). Thus, we designated the TTA as the COI start codon. Only a few other sequenced coleopteran insects have a typical ATN start codon, but these are all located inside neighboring tRNA ${ }^{\text {Tyr }}$ (Fig. 3). Thus, Sheffield et al. (2008) previously suggested that start codon for COI genes should be chosen to minimize 


Polyphaga
Apatides fortis
Chrysochroa fulgidissima
Acmaeodera sp.
Cyphon sp.
Pyrophorus divergens
Rhagophthalmus lufengensis
Rhagophthalmus ohbai
Pyrocoelia rufa
Chauliognathus opacus
Protaetia brevitarsiss
Polyphylla laticollis manchurica
Rhopaea magnicornis
Metopodontus blanchardi
Lucanus mazama
Priasilpha obscura
Cucujus clavipes
Anoplophora glabripennis
Psacothea hilaris
Crioceris duodecimpunctata
*Tribolium castaneum
Adelium sp.
Mordella atrata
Chaetosoma scaritides
Naupactus xanthographus
Sphenophorus sp.
Euspilotus scissus
Necrophila americana
Tropisternus sp.
Myxophaga
Sphaerius sp.
*Hydroscapha granulum
Adephaga
Trachypachus holmbergi
Calosoma sp.
Aspidytes niobe
Macrogyrus oblongus
Archostemata
Tetraphalerus bruchi

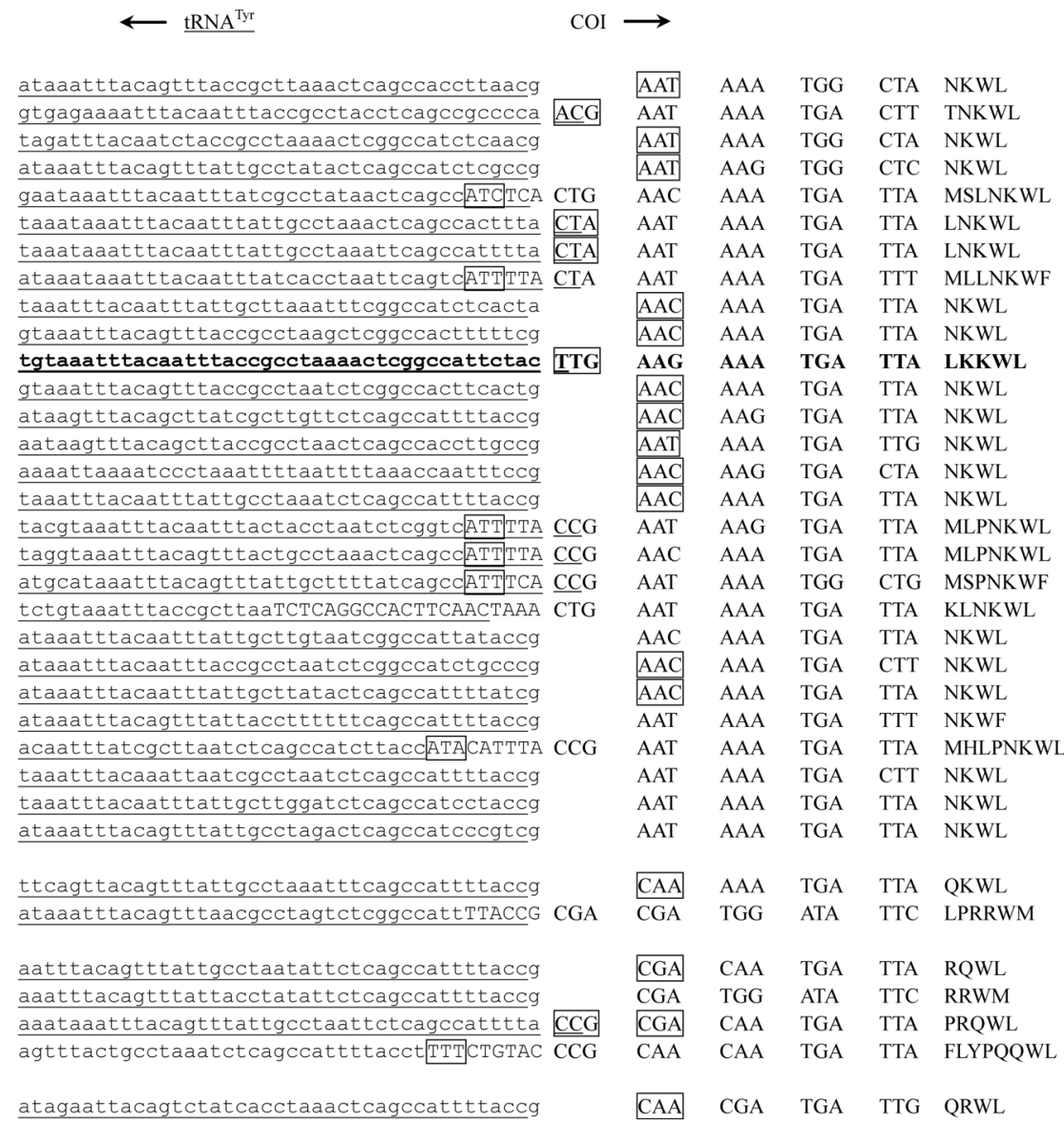

Fig. 3. Alignment of the initiation context of COI genes of coleopteran insects including that of Polyphylla laticollis manchurica. The first four to seven codons are shown in uppercase letters on the right-hand side of the figure. Underlined nucleotides indicate the adjacent partial sequence of $\mathrm{RRNA}^{\mathrm{Tyr}}$. Arrows indicate the direction of transcription. Boxed nucleotides indicate currently known translation initiators for the COI of coleopteran. The start codon for P. 1. manchurica was designated respectively as TTG.

intergenic spacer sequences and gene overlaps. In this regard, they proposed asparagines (AAT or AAC) as the start codon for COI gene, because those are the first non-overlapping inframe codons, and found at the corresponding position in all sequenced Polyphaga in Coleoptera (Fig. 3; Sheffield et al., 2008). Furthermore, they hypothesized that asparagines may function as a molecular synapomorphy for Polyphaga (Sheffield et al., 2008). However, our newly sequenced $P$. 1 . manchurica, which belongs to Polyphaga, instead have AAG (Lysine) at the corresponding position and have the typical TTG precedent to AAG. Thus, our P. 1. manchurica is the only example that does not follow the unanimous COI start codon in Polyphaga. The P. 1. manchurica ATPase 8 also has the TTG start codon (Fig. 4). Previously, the TTG codon was found in ND1 gene for coleopteran P. rufa (Bae et al., 2004) and dipteran Anopheles quadrimaculatus (Mitchell et al., 1993), and COI gene for lepidopteran Caligula boisduvalii (Hong et al., 2008), but has never been found for the start codon for ATPase8 in Coleoptera (data not shown).

Eleven of the 13 PCGs have a complete termination codon of TAA or TAG, but the COII and COIII genes harbor the incomplete termination codon, $\mathrm{T}$ (Table 2). The most common interpretation of this phenomenon is that TAA termini are created via post-transcriptional polyadenylation (Ojala et al., 1981).

\section{tRNA and rRNA genes}

The $P$. 1. manchurica mitogenomes harbors 22 tRNA genes that are interspersed thorough genomes (Fig. 5). Except for tRNA $^{\text {Ser }}(\mathrm{AGN})$, the dihydrouridine (DHU) arm of which forms a simple loop, all tRNAs were folded into the typical clover-leaf structure. The aberrant tRNA ${ }^{\text {Ser }}(\mathrm{AGN})$ has been reported in many 


Polyphaga
Apatides fortis
Chrysochroa fulgidissima
Acmaeodera sp.
Cyphon sp.
Pyrophorus divergens
Rhagophthalmus lufengensis
Rhagophthalmus ohbai
Pyrocoelia rufa
Chauliognathus opacus
Protaetia brevitarsiss
Polyphylla laticollis manchurica
Rhopaea magnicornis
Metopodontus blanchardi
Lucanus mazama
Priasilpha obscura
Cucujus clavipes
Anoplophora glabripennis
Psacothea hilaris
Crioceris duodecimpunctata
Tribolium castaneum
Adelium sp.
Mordella atrata
Chaetosoma scaritides
Naupactus xanthographus
Sphenophorus sp.
Euspilotus scissus
Necrophila americana
Tropisternus sp.
Myxophaga
Sphaerius sp.
Hydroscapha granulum
Adephaga
Trachypachus holmbergi
Calosoma sp.
Aspidytes niobe
Macrogyrus oblongus
Archostemata
Tetraphalerus bruchi

\begin{tabular}{|c|c|c|c|c|c|c|}
\hline $\mathrm{tRNA}^{\text {Asp }} \longrightarrow$ & ATPase8 & & & & & \\
\hline ttttaaaataattacttagtaataaaccccg & ATT & ССТ & CAA & ATA & GCC & IPQMA \\
\hline ttaaggaataataaaaattattgagcgcccagctattccta & ATA & $\mathrm{CCA}$ & $\mathrm{CAA}$ & ATA & GCA & MPQMA \\
\hline ttagcttgtcgagctaaattattaactactaataattttt & ATT & $\mathrm{CCA}$ & CAA & GCG & CTA & IPQAL \\
\hline aggttgtcaatctaaaatcattttaaataaatatttttta & ATT & CCT & CAA & ATA & GCT & IPQMA \\
\hline tagcttgtcaagctaaaattattaatcattaataattttta & ATT & $\mathrm{CCG}$ & CAA & ATA & GCT & IPQMA \\
\hline acttgtcatgtttaaataattattataaataataattttta & ATT & $\mathrm{CCA}$ & $\mathrm{CAA}$ & ATA & GCA & IPQMA \\
\hline acttgtcatgtttaaataattattataaataataattttta & ATT & $\mathrm{CCA}$ & CAA & ATA & GCA & IPQMA \\
\hline ttaatttgtcaaattaaataattttcaaaaataattttta & ATT & $\mathrm{CCA}$ & CAA & ATA & $\mathrm{AGC}$ & IPQMS \\
\hline cgttagtttgtcaaactaaaatcattgaaaaataattttta & ATT & $\mathrm{CCA}$ & CAA & ATA & TCA & IPQMS \\
\hline$\overline{\text { ttaatttgtcaagttaaataatcattattgataactttta }}$ & ATC & $\mathrm{CCA}$ & $\mathrm{CAA}$ & ATA & TCA & IPQMS \\
\hline taacttgtcaagttagaattacctcgaagcggtagttttta & TTG & CCT & CAA & ATA & GCA & LPQMA \\
\hline attagtttgtcaaactaaaataacctttaggtagttttta & ATT & $\mathrm{CCA}$ & CAA & ATA & ATA & IPQMM \\
\hline cgttagtttgtcaaactaaattacttataggtatcctta & ATT & $\mathrm{CCA}$ & CAA & ATA & GCT & IPQMA \\
\hline cattaacttgtcatattaaaattatcagctgatagtcttta & ATT & ССТ & CAA & ATA & GCC & IPQMA \\
\hline tttgtcaaactaaattattaaccccattagataattttct & ATT & ССТ & $\mathrm{CAA}$ & ATA & ATA & IPQMM \\
\hline ttaatttgtcaaattaaaattatttaaataaataattttct & ATT & ССТ & CAA & ATA & GCC & IPQMA \\
\hline$\overline{\text { tagcttgtcaagctaaaattattattaaataataattttta }}$ & ATT & ССТ & CAA & ATA & GCA & IPQMA \\
\hline tagcttgtcaagctaaaattattataaattaataattttta & ATT & $\mathrm{CCA}$ & CAA & ATA & GCA & IPQMA \\
\hline ttagtttgtcaaactaaaattatttgtgtaaa & $\underline{\text { ATT }}$ & $\mathrm{CCT}$ & CAA & ATA & GCA & IPQMA \\
\hline caaactaaagtcaacgtaaacctgttagtttttaattcctc & ATT & $\mathrm{CCT}$ & $\mathrm{CAA}$ & ATA & GCC & IPQMA \\
\hline tatattaaattacct & ATA & $\mathrm{CCA}$ & CAA & ATA & GCT & IPQMA \\
\hline attaacttgtcaagttaaaattaattcattattagttttta & ATT & ССТ & CAA & ATA & $\mathrm{GCT}$ & IPQMA \\
\hline atattttcctgcaaggtcaaagtaactttaagtgatttttt & ATA & $\mathrm{CCA}$ & CAA & ATA & GCT & IPQMA \\
\hline$\overline{\text { ttagtttgtcaaactaaaattattaactataataattttta }}$ & ATT & $\mathrm{CCA}$ & CAA & ATA & GCT & IPQMA \\
\hline tcttaaaccatttaatagtaaattagtacttacttctaatg & ATC & $\mathrm{CCA}$ & CAA & ATA & TCT & IPQMS \\
\hline tcttaaccattttatagtaaactaacgattacttctaatg & ATT & ССТ & CAA & ATA & GCA & IPQMA \\
\hline cttaaccatcccatagtatattaacgaatacttctaatgg & ATT & ССТ & CAA & ATA & GCA & IPQMA \\
\hline tcttaaaccacattatagtaaattagcacttacttctaatg & ATT & $\mathrm{CCA}$ & CAA & ATA & GCC & IPQMA \\
\hline gtatattaacgaatacttctaatgaaatacctaattttata & ATT & $\mathrm{CCA}$ & CAA & ATA & GCA & IPQMA \\
\hline gcatgtcaaactaaaattattaatatttttaatattcttta & ATA & $\mathrm{CCA}$ & CAA & ATA & GCT & MPQMA \\
\hline agaatgtcaaactaaaattattaaattattaatattcttta & ATT & $\mathrm{CCA}$ & CAA & ATA & GCC & IPQMA \\
\hline agaatgtcaaactaaaattattaatatattaatattctttg & ATT & СCT & CAA & ATA & GCT & IPQMA \\
\hline tagaatgtcaaactaaaattattaataattaatatttctta & ATT & CCT & CAA & ATA & GCA & IPQMA \\
\hline tagaatgtcaaactgaaattattaaaattaatattcttta & ATC & ССТ & CAA & ATA & GCC & IPQMA \\
\hline & ATG & $\mathrm{CCT}$ & CAA & ATA & TCA & PQMS \\
\hline
\end{tabular}

Fig. 4. Alignment of the initiation context of ATPase8 gene of coleopteran insects, including that of Polyphylla laticollis manchurica. The first five codons are shown in uppercase letters on the right-hand side of the figure. Underlined nucleotides indicate the adjacent partial sequence of tRNA ${ }^{\text {Asp }}$. Arrows indicate the direction of transcription. Boxed nucleotides indicate currently known translation initiators for the ATPase 8 gene of coleopteran insects. The start codon for $P$. l. manchurica was designated respectively as TTG.

metazoan species, including insects (Wolstenholme 1992; Garey and Wolstenholme, 1989). For the proper function of a tRNA the DHU arm, which is involved in tertiary interaction requires proper folding (Rich and RajBhandary, 1976). The nuclear magnetic resonance analysis from nematodes has shown that the aberrant $\mathrm{RNA}^{\mathrm{ser}}$ (AGN) also functions in a similar way to that of usual tRNAs by structural adjustment to fit in the ribosome (Ohtsuki et al., 2002).

The size of tRNAs ranged from 61 (tRNA ${ }^{\text {Cys }}$ ) to 71 bp (tRNA ${ }^{\text {Lys }}$ ) in P. 1. manchurica (Table 2). Interestingly, $\mathrm{RRNA}^{\mathrm{Lys}}$ is often slightly larger than tRNAs in many other coleopteran mitogenomes. In fact, 29 among 35 coleopteran species analyzed in this study ranked the tRNA ${ }^{\text {Lys }}$ as the longest tRNA at 71 bp (data not shown). In the varying tRNA size, the size of aminocyle stem as $7 \mathrm{bp}$, anticodon loops as $7 \mathrm{bp}$, and anticodon stem as $5 \mathrm{bp}$ were all well conserved in all $P$. 1 manchurica tRNAs. Most of size variation among tRNAs stemmed from the length variation in DHU and TYC arms, within which loop sizes ( $3 \sim 13 \mathrm{bp}$ ) are more variable than stem sizes ( $3 \sim$ $7 \mathrm{bp}$ ). With the numerous number of G-U base pairs, which form a weak bond in the tRNAs the P. 1 manchurica tRNAs contained 11 mismatches (three U-C, and each two A-C, U-U, G-A, and A-A mismatches) (Fig. 5). As with all other insect mitogenome sequences, two rRNA genes were detected in P. 1 manchurica. The lrRNA is located between tRNA ${ }^{\text {Leu }}(\mathrm{CUN})$ and tRNA ${ }^{\mathrm{Val}}$ and the srRNA is located between $\mathrm{RNA}^{\mathrm{Val}}$ and the presumable $\mathrm{A}+\mathrm{T}$-rich region, respectively (Fig. 1).

\section{Nucleotide composition, codon usage, and skewness}

The nucleotide composition of the mitogenome of $P$. 1 . manchurica is also biased toward A/T content at $69.9 \%$ (Table 3 ). This value is well within the range found in the sequenced 

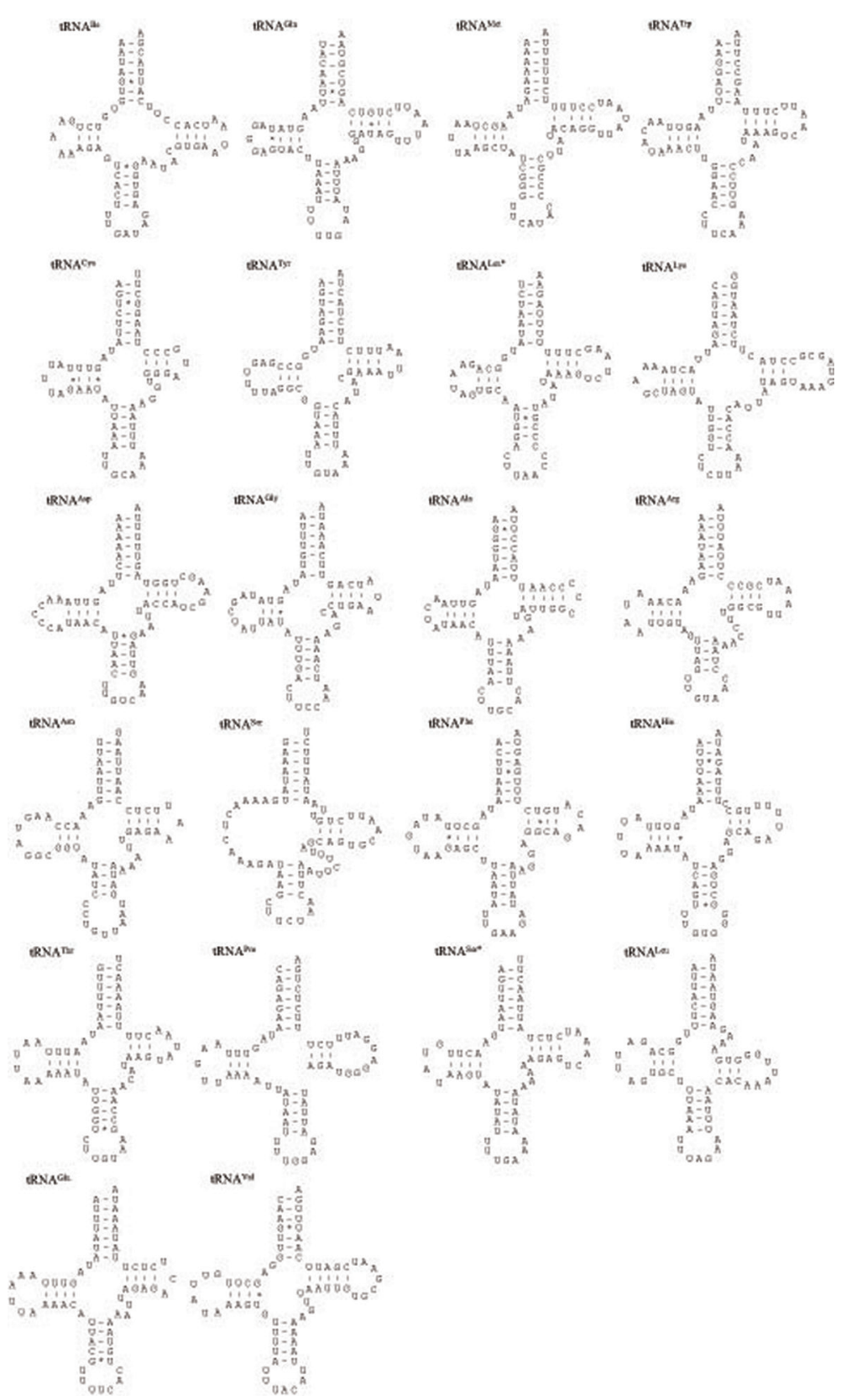

Fig. 5. Predicted secondary clover-leaf structures for the 22 tRNA genes of Polyphylla laticollis manchurica. The tRNAs are labeled with the abbreviations of their corresponding amino acids. The one-letter symbols L, L*, S and $\mathrm{S}^{*}$ denote tRNA ${ }^{\text {Leu }}(C U N)$, tRNA ${ }^{\text {Leu }}(U U R)$, $\operatorname{tRNA}^{\text {Ser }}(\mathrm{AGN})$, and tRNA ${ }^{\text {Ser }}(\mathrm{UCN})$, respectively. Arms of tRNAs (clockwise from top) are the amino acid acceptor (AA) arm, TYC (T) arm, the anticodon (AC) arm, and the dihydrouridine (DHU) arm. Nucleotide sequences from 5' to 3' are indicated from the left side of the amino acid stem. Dashes (-) indicate Watson-Crick base-pairing, and centered asterisks $\left({ }^{*}\right)$ indicate G-U base-pairing.

coleopteran insects, where these values range from $67.2 \%$ in Apatides fortis to $80.8 \%$ in Sphaerius sp. (Table 3). To evaluate the degree of the base bias, the AT-skew and GC-skew each in the whole genome and whole PCGs from the major strand and each major- and minor-strand PCGs was measured from coleopteran insects, including P. 1. manchurica (Table 4). Overall, whole genomes of all coleopteran species including the $P$. 1. manchurica are obviously A- and C-skewed, whereas whole PCGs are T- and $\mathrm{C}$-skewed, indicating that Ts are clearly more favored over As in the PCGs, and the evolutionary pattern of PCGs differ from the remaining genes. In the majority of coleopteran species, including P. 1. manchurica, the major-strand, in which nine PCGs (ND2, 


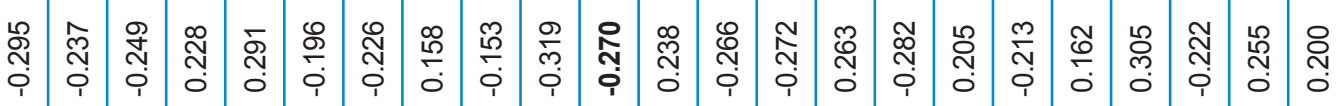

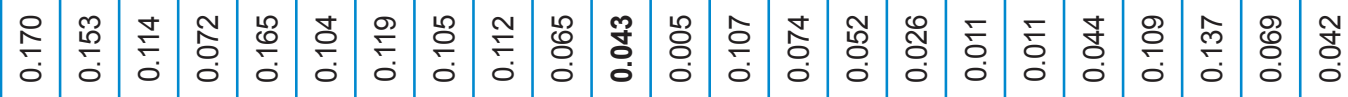
它

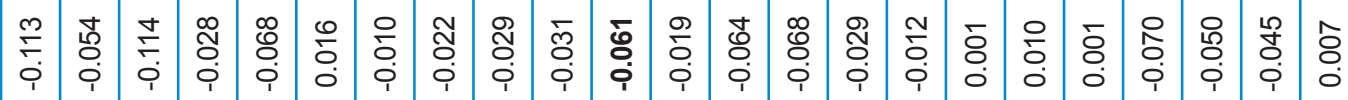

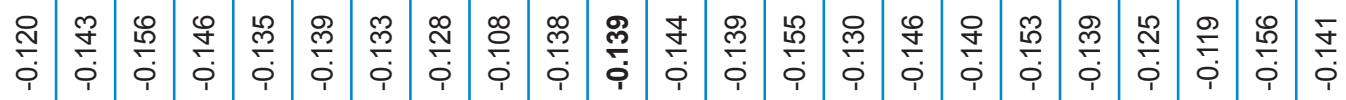

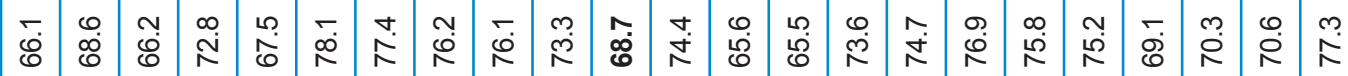

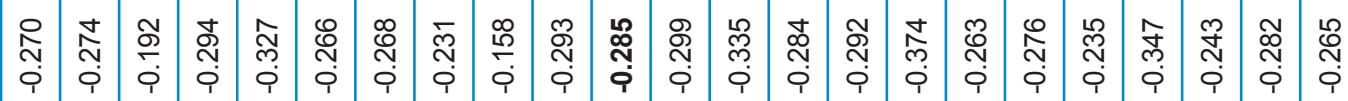

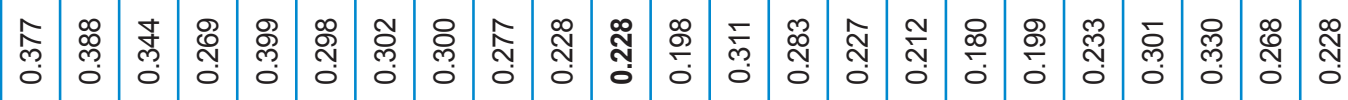

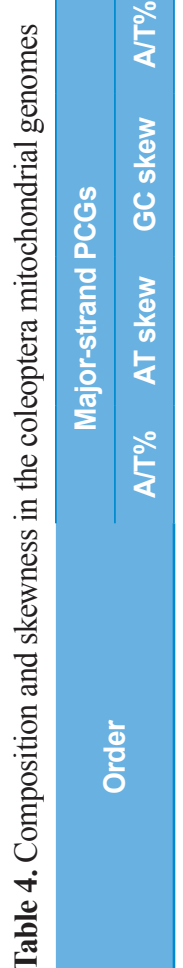

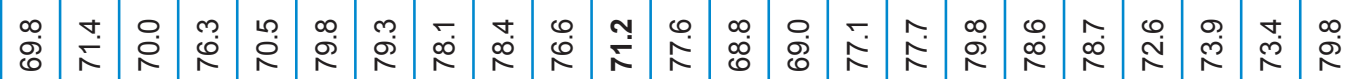

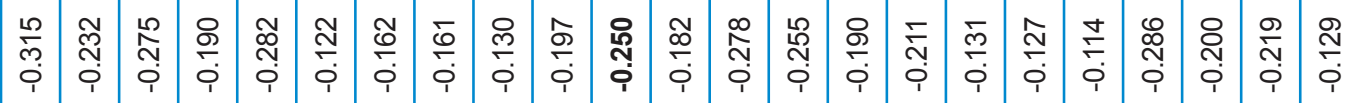

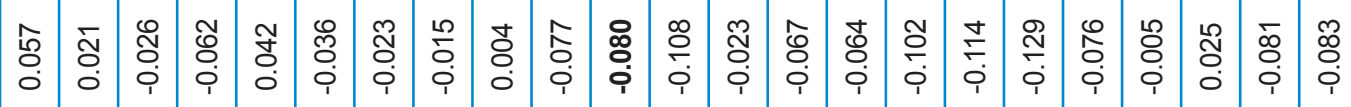

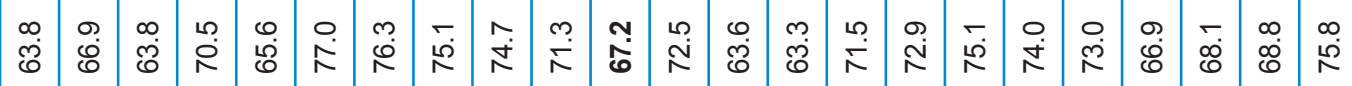




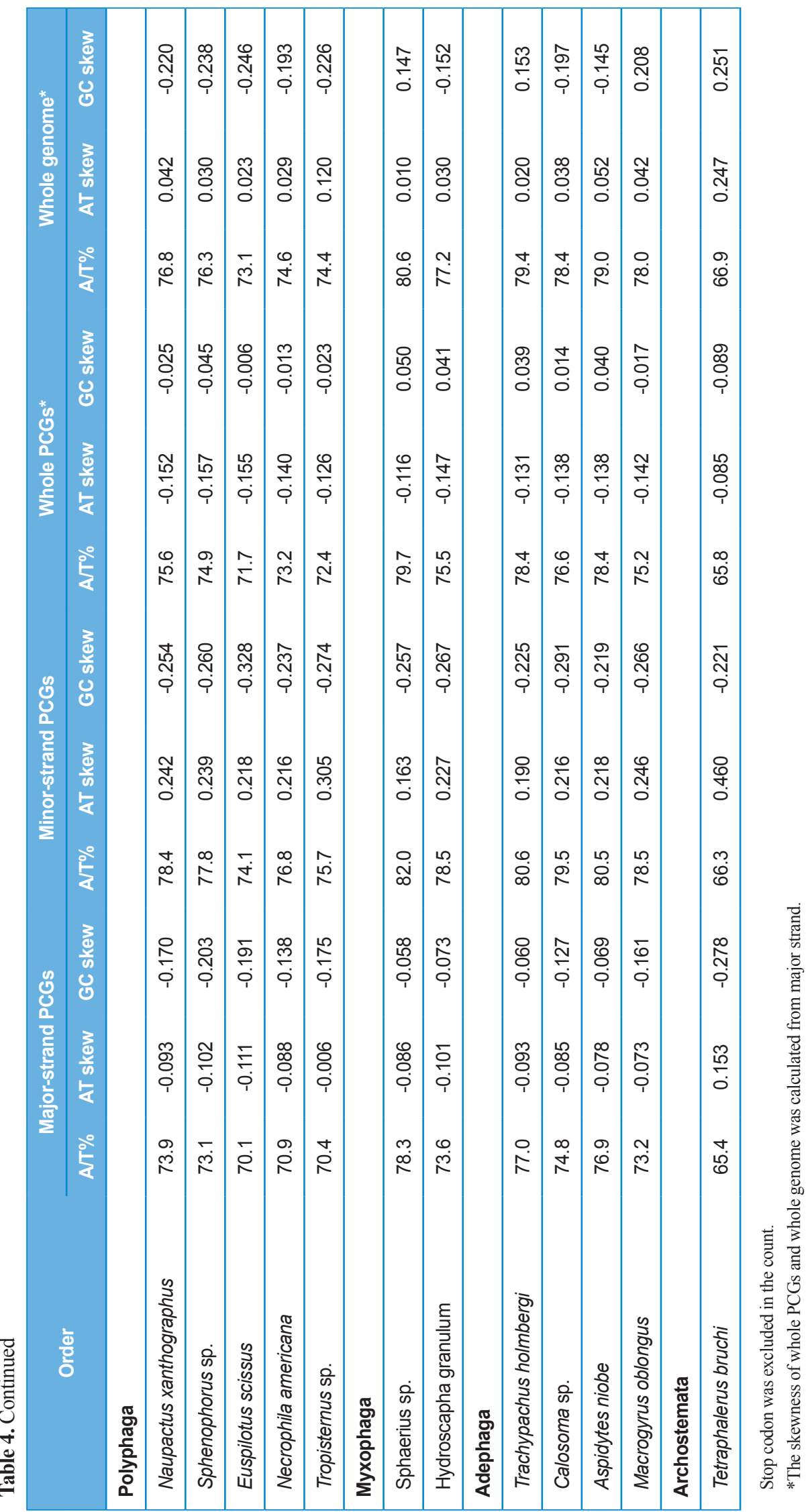


Table 5. Frequency of four most frequent codons of coleopteran insects

\begin{tabular}{|c|c|c|c|c|c|}
\hline \multirow[b]{2}{*}{ Species } & \multicolumn{5}{|c|}{ codon } \\
\hline & $\begin{array}{l}\text { TTA } \\
\text { (L) }\end{array}$ & $\begin{array}{c}\text { ATT } \\
\text { (I) }\end{array}$ & $\begin{array}{l}\text { TTT } \\
(\mathrm{F})\end{array}$ & $\begin{array}{l}\text { ATA } \\
\text { (I) }\end{array}$ & Total \\
\hline \multicolumn{6}{|l|}{ Polyphaga } \\
\hline Apatides fortis & 5.62 & 5.40 & 5.43 & 4.18 & 20.63 \\
\hline Chrysochroa fulgidissima & 5.90 & 7.39 & 4.61 & 7.31 & 25.21 \\
\hline Acmaeodera sp. & 5.29 & 7.07 & 6.66 & 4.26 & 23.28 \\
\hline Cyphon sp. & 9.81 & 8.84 & 6.09 & 7.90 & 32.64 \\
\hline Pyrophorus divergens & 4.48 & 6.43 & 4.97 & 6.26 & 22.14 \\
\hline Rhagophthalmus lufengensis & 10.60 & 10.12 & 7.63 & 9.12 & 37.47 \\
\hline Rhagophthalmus ohbai & 10.46 & 9.89 & 7.23 & 9.10 & 36.68 \\
\hline Pyrocoelia rufa & 9.60 & 10.27 & 7.51 & 8.59 & 35.97 \\
\hline Chauliognathus opacus & 9.87 & 9.14 & 7.12 & 7.83 & 33.96 \\
\hline Protaetia brevitarsiss & 10.10 & 8.70 & 6.08 & 7.56 & 32.44 \\
\hline Polyphylla laticollis manchurica & 8.29 & 7.32 & 5.56 & 7.05 & 28.22 \\
\hline Rhopaea magnicornis & 11.49 & 9.41 & 6.06 & 7.36 & 34.32 \\
\hline Metopodontus blanchardi & 4.93 & 6.63 & 5.01 & 5.90 & 22.47 \\
\hline Lucanus mazama & 5.51 & 7.02 & 4.41 & 6.06 & 23.00 \\
\hline Priasilpha obscura & 9.82 & 9.60 & 6.87 & 8.36 & 34.65 \\
\hline Cucujus clavipes & 10.51 & 9.35 & 6.56 & 8.16 & 34.58 \\
\hline Anoplophora glabripennis & 12.45 & 10.52 & 5.86 & 8.57 & 37.40 \\
\hline Psacothea hilaris & 11.92 & 10.06 & 5.23 & 8.50 & 35.71 \\
\hline Crioceris duodecimpunctata & 11.69 & 8.99 & 5.93 & 8.69 & 35.30 \\
\hline Tribolium castaneum & 6.62 & 8.32 & 4.95 & 6.54 & 26.43 \\
\hline Adelium sp. & 7.10 & 7.32 & 5.72 & 6.61 & 26.75 \\
\hline Mordella atrata & 8.10 & 8.45 & 4.97 & 6.74 & 28.26 \\
\hline Chaetosoma scaritides & 11.80 & 10.39 & 7.19 & 8.98 & 38.36 \\
\hline Naupactus xanthographus & 11.88 & 9.48 & 5.78 & 9.02 & 36.16 \\
\hline Sphenophorus sp. & 10.58 & 9.91 & 5.24 & 8.88 & 34.61 \\
\hline Euspilotus scissus & 8.57 & 8.62 & 5.48 & 7.49 & 30.16 \\
\hline Necrophila americana & 9.82 & 9.17 & 5.95 & 7.57 & 32.51 \\
\hline Tropisternus sp. & 8.82 & 7.84 & 5.17 & 6.25 & 28.08 \\
\hline \multicolumn{6}{|l|}{ Myxophaga } \\
\hline Sphaerius sp. & 13.56 & 10.95 & 7.68 & 8.90 & 41.09 \\
\hline Hydroscapha granulum & 12.36 & 9.03 & 6.41 & 8.74 & 36.54 \\
\hline \multicolumn{6}{|l|}{ Adephaga } \\
\hline Trachypachus holmbergi & 13.29 & 9.77 & 7.43 & 9.21 & 39.70 \\
\hline Calosoma sp. & 12.19 & 9.21 & 7.09 & 8.56 & 37.05 \\
\hline Aspidytes niobe & 12.55 & 10.65 & 8.21 & 9.41 & 40.82 \\
\hline Macrogyrus oblongus & 10.72 & 9.24 & 6.89 & 9.26 & 36.11 \\
\hline \multicolumn{6}{|l|}{ Archostemata } \\
\hline Tetraphalerus bruchi & 4.37 & 5.26 & 4.97 & 6.02 & 20.62 \\
\hline Average & 9.45 & 8.74 & 6.11 & 7.68 & 31.98 \\
\hline
\end{tabular}

ND3, ND6, COI, COII, COIII, ATPase6, ATPase8, and CytB) are encoded is slightly T-skewed (AT skew $=-0.129 \sim 0.153$ ), whereas the minor-strand, in which four PCGs (ND1, ND4, ND4L, and ND5) are encoded is obviously A-skewed (AT skew $=0.163$ $\sim 0.460$ ), although both strands are C-skewed (Table 4). Thus, the two strands are sharply distinct in A/T-skewness, indicating that mutational pressures that favor Ts or As are starkly different between the two strands. It has been suggested that the lagging strand, equivalent to the major strand, should be more prone to chemical conversion of As to Gs and Cs to Ts, by the mechanism called deamination than the leading strand, and this may have resulted in the enriched Ts and Gs in the lagging strand, and As and Cs in the leading strand (Reyes et al., 1998). Nevertheless, current coleopteran mitogenomes pretty strongly display C-skewness rather than G-skewness in the major strand (Table 4). Thus, the strand-based inequality has yet to be clearly understood.

The genome-wise $\mathrm{A} / \mathrm{T}$ bias is also reflected in the codon usage of P. 1. manchurica mitogenomes (Table 5). The codons TTA (Leu), ATT (Ile), TTT (Phe), and ATA (Met) are the four most frequently used codons in the P. 1. manchurica PCGs, accounting for $28.22 \%$ and on average these four codons accounted for $31.98 \%$ in Coleoptera (Table 5). Considering 60 codons are available, excluding each two start and stop codons (ATA, ATG, TAA, and TAG) the overuse of these four codons is obvious. These four codons are all comprised of A or T nucleotides, thus indicating the biased usage of $\mathrm{A}$ and $\mathrm{T}$ nucleotides in the coleopteran insects including P. 1. manchurica PCGs.

The analysis of the base composition at each codon position of the concatenated 13 PCGs of P. 1. manchurica showed $68.6 \%$ of the A/T content in the third codon position. This value is higher than that of the first (66.4\%) and second (66.2\%) codon positions, and on average, the $\mathrm{A} / \mathrm{T}$ content in the third codon position was $74.9 \%$, ranging from $65.4 \%$ to $82.1 \%$ in Coleoptera (Table 6). In a comparison among species-diverse insect orders, Hymenoptera is the highest on average at 93.1\% (Hong et al., 2008), Lepidoptera is next at 92.1\% (Kim et al., 2010), and Diptera rank third at $92.0 \%$ (Cameron et al., 2009), indicating that the Coleoptera is the least A/T-biased. Probably, this aspect has implications for phylogenetic analysis because of the different degrees of $\mathrm{A} / \mathrm{T}$ bias, resulting in compositional heterogeneity among insect orders as a major source of systematic bias in phylogeny (Jermiin et al., 2004; Sheffield et al., 2009). 
(1)

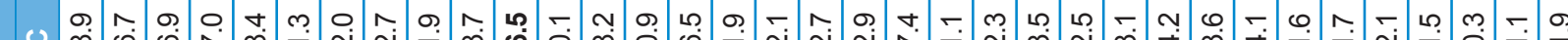
$\frac{5}{6}$

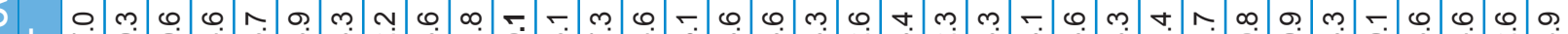
尚

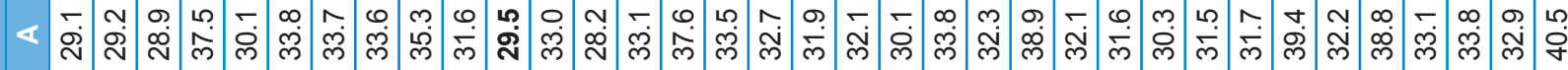

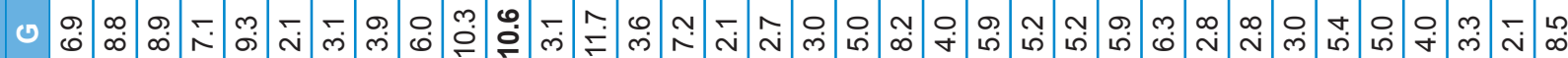

을

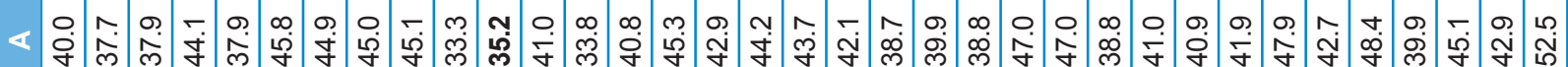

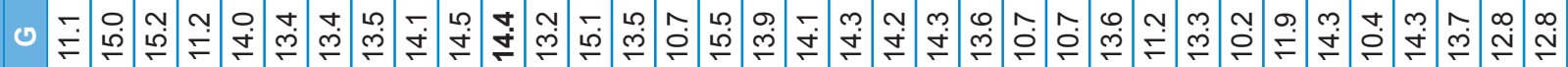

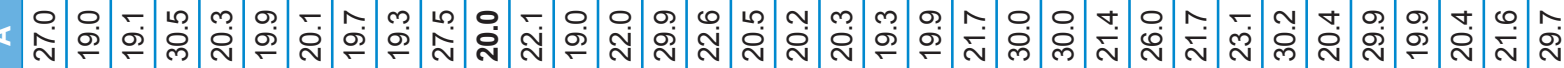

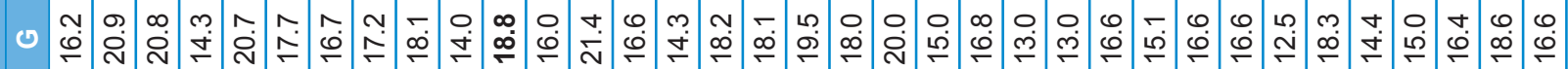

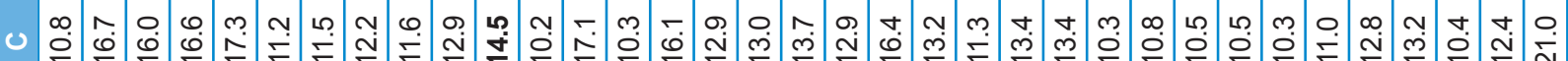

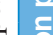

m.

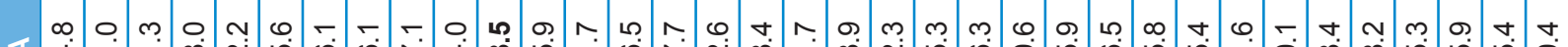

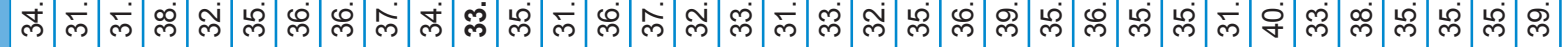




\section{Acknowledgements}

This work was supported by research grants from the National Institute of Biological Resources-"The Genetic Evaluation of Important Biological Resources" awarded to Iksoo Kim.

\section{References}

Arnoldi FG, Ogoh K, Ohmiya Y and Viviani VR (2007) Mitochondrial genome sequence of the Brazilian luminescent click beetle Pyrophorus divergens (Coleoptera: Elateridae): Mitochondrial genes utility to investigate the evolutionary history of Coleoptera and its bioluminescence. Gene 405, 1-9.

Bae JS, Kim I, Sohn HD, Jin BR (2004) The mitochondrial genome of the firefly, Pyrocoelia rufa: complete DNA sequence, genome organization, and phylogenetic analysis with other insects. Mol Phylogenet Evol 32, 978-985.

Boore JL (1999) Animal mitochondrial genomes. Nucleic Acids Res 27, $1767-1780$

Burland TG (2000) DNASTAR's Lasergene sequence analysis software. Methods Mol Biol 132, 71-91.

Cameron SL, Sullivan J, Song H, Miller KB, Whiting FW (2009) mitochondrial genome phylogeny of the Neuropterida (lacewings, alderflies and snakeflies) and their relationship to the other holometabolous insect orders. Zool Scr 38, 575-590.

Carapelli A, Vannini L, Bardi F, Boore JL, Beani L, Dallai R and Frati F (2006) The mitochondrial genome of the entomophagous endoparasite Xenos vesparum (Insecta: Strepsiptera). Gene 376, 248 259.

Friedrich M, Muquim N (2003) Sequence and phylogenetic analysis of the complete mitochondrial genome of the flour beetle Tribolium castanaeum. Mol Phylogenet Evol 26, 502-512.

Garey JR and Wolstenholme DR (1989) Platyhelminth mitochondrial DNA: evidence for early evolutionary origin of a tRNA ${ }^{\text {ser }}(A G N)$ that contains a dihydrouridine arm replacement loop, and of serinespecifying AGA and AGG codons. J Mol Evol 28, 374-387.

Hammond PM (1992) Species inventory; in Global biodiversity, status of the earth's living resources. Grrombridge B (ed.), pp. 17-39. Chapman and Hall, London.

Hong MY, Jeong HC, Kim MJ, Jeong HU, Lee SH, Kim I (2009) Complete mitogenome sequence of the jewel beetle, Chrysochroa fulgidissima (Coleoptera: Buprestidae). Mitochondrial DNA 20, 46-
60.

Hong MY, Lee EM, Jo YH, Park HC, Kim SR, Hwang JS, Jin BR, Kang PD, Kim KG, Han YS and Kim I (2008) Complete nucleotide sequence and organization of the mitogenome of the silk moth Caligula boisduvalii (Lepidoptera: Saturniidae) and comparison with other lepidopteran insects. Gene 413, 49-57.

Jermiin L, Ho SY, Ababneh F, Robinson J, Larkum AW (2004) The biasing effect of compositional heterogeneity on phylogenetic estimates may be underestimated. Syst Biol 53, 638-43.

Kim KG, Hong MY, Kim MJ, Im HH, Kim MI, Seo SJ, Lee SH and Kim I (2009) Complete mitochondrial genome sequence of the yellow-spotted long-horned beetle Psacothea hilaris (Coleoptera: Cerambycidae) and phylogenetic analysis among coleopteran insects. Mol Cells 27, 429-441.

Kim I, Cha SY, Kim MA, Lee YS, Lee KS, Choi YS, Hwang JS, Jin BR, Han YS (2007) Polymorphism and genomic structure of the A?T-rich region of mitochondrial DNA in the oriental mole cricket, Gryllotalpa orientalis (Orthoptera: Gryllotalpidae). Biochem Genet $45,589-610$.

Kim MJ, Im HH, Lee KY, Han YS, Kim I (2013a) Complete mitochondrial genome of the whiter-spotted flower chafer, Protaetia brevitarsis (Coleoptera: Scarabaeidae). Mitochondrial DNA In press (DOI: 10.3109/19401736.2013.792064).

Kim MJ, Kang AR, Jeong HC, Kim K-G, Kim I (2011) Reconstructing intraordinal relationships in Lepidoptera using mitochondrial genome data with the description of two newly sequenced lycaenids, Spindasis takanonis and Protantigius superans (Lepidoptera: Lycaenidae). Mol Phylogenet Evol 61, 436-445.

Kim MJ, Kim K-G, Kim SR, Kim I (2013b) Complete mitochondrial genome of the two-spotted stag beetle, Metopodontus blanchardi (Coleoptera: Lucanidae). Mitochondrial DNA In press (DOI: 10.3109/19401736.2013.825788).

Kim MJ, Wan X, Kim I (2012) Complete mitochondrial genome of the seven-spotted lady beetle, Coccinella septempunctata (Coleoptera: Coccinellidae) Mitochondrial DNA 23, 179-181.

Kim MJ, Wan X, Kim KG, Hwang JS, Kim I (2010) Complete nucleotide sequence and organization of the mitogenome of endangered Eumenis autonoe (Lepidoptera: Nymphalidae). Afr J Biotechnol 9, 735-54.

Lewis DL, Farr CL, Farquhar AL, Kaguni LS (1994) Sequence, organization, and evolution of the $\mathrm{A}+\mathrm{T}$ region of Drosophila melanogaster mitochondrial DNA. Mol Biol Evol 11, 523-538.

Li X, Ogoh K, Ohba N, Liang X, Ohmiya Y (2007) Mitochondrial 
genomes of two luminous beetles, Rhagophthalmus lufengensis and $R$. ohbai (Arthropoda, Insecta, Coleoptera). Gene 392, 196-205.

Lowe TM, Eddy SR (1997) tRNAscan-SE: A program for improved detection of transfer RNA genes in genomic sequence. Nucleic Acids Res 25, 955-964.

Mitchell SE, Cockburn AF and Seawright JA (1990) The mitochondrial genome of Anopheles quadrimaculatus species A: complete nucleotide sequence and gene organization. Genome 36, 1058-1073.

Ohtsuki T, Sato A, Watanabe Y and Watanabe K (2002) A unique serinespecific elongation factor Tu found in nematode mitochondria. Nat Struct Biol 9, 669-673.

Ojala D, Montoya J, Attardi G (1981) tRNA punctuation model of RNA processing in human mitochondria. Nature 290, 470-474.

Perna NT, Kocher TD (1995) Patterns of nucleotide composition at four fold degenerate sites of animal mitochondrial genomes. J Mol Evol $41,353-358$

Pons J, Ribera I, Bertranpetit J, Balke M (2010) Nucleotide substitution rates for the full set of mitochondrial protein-coding genes in Coleoptera. Mol Phylogenet Evol 56, 796-807.

Reyes A, Gissi C, Pesole G and Saccone C (1998) Asymmetrical directional mutation pressure in the mitochondrial genome of mammals. Mol Biol Evol 15, 957-966.

Sheffield NC, Song H, Cameron SL, Whiting MF (2008) A comparative analysis of mitochondrial genomes in Coleoptera (Arthropoda: Insecta) and genome descriptions of six new beetles. Mol Biol Evol $25,2499-2509$

Sheffield NC, Song H, Cameron SL, Whiting MF (2009) Nonstationary evolution and compositional heterogeneity in beetle mitochondrial phylogenomics. Syst Biol 58, 381-394.

Song H, Sheffield NC, Cameron SL, Miller KB and Whiting MF (2010) When phylogenetic assumptions are violated: base compositional heterogeneity and among-site rate variation in beetle mitochondrial phylogenomics. Syst Entomol 35, 429-448.

Stewart JB, Beckenbach AT (2003) Phylogenetic and genomic analysis of the complete mitochondrial DNA sequence of the spotted asparagus beetle Crioceris duodecimpunctata. Mol Phylogenet Evol 26, 513-526.

Taanman JW (1999). The mitochondrial genome: structure, transcription, translation and replication. Biochim Biophys Acta1410, 103123.

Thompson JD, Gibson TJ, Plewniak F, Jeanmougin F, Higgins DG (1997) The CLUSTAL X windows interface: flexible strategies for multiple sequence alignment aided by quality analysis tools. Nucleic Acids Res 24, 173-216.

Wan X, Kim MI, Kim MJ, Kim I (2012) Complete mitochondrial genome of the free-living earwig, Challia fletcheri (Dermaptera: Pygidicranidae) and phylogeny of Polyneoptera. PLoS ONE 7, e42056.

Wang AR, Kim MJ, Park JS, Choi YS, Thapa R, Lee KY, Kim I (2013) Complete mitochondrial genome of the dwarf honeybee, Apis florea (Hymenoptera: Apidae). Mitochondrial DNA 24, 208-210.

Wolstenholme DR (1992) Animal mitochondrial DNA: structure and evolution; in International Review of Cytology Wolstenholme DR, Jeon KW (eds.) pp. 173-216. Academic Press, New York.

Won, BH, Kwon YJ, Kim, SS, Kim, W, et al. (1998) Endangered wild species in Korea. Seoul, Korea: Kyo-Hak Publishing Co.

Zhang DX, Hewitt GM (1997) Insect mitochondrial control region: A review of its structure, evolution and usefulness in evolutionary studies. Biochem Syst Evol 25, 99-120.

Zhou Z, Huang Y, Shi F (2007) The mitochondrial genome of Ruspolia dubia (Orthoptera: Conocephalidae) contains a short A+T-rich region of $70 \mathrm{bp}$ in length. Genome 50, 855-866. 